\title{
DINÂMICA DA ACUMULAÇÃO DE CAPACIDADES INOVADORAS: EVIDÊNCIAS DE EMPRESAS DE SOFTWARE NO RIO DE JANEIRO E EM SÃO PAULO
}

DYNAMICS OF ACCUMULATION OF CAPABILITY FOR INNOVATION: EVIDENCE FROM SOFTWARE FIRMS IN RIO DE JANEIRO AND SÃO PAULO DINÁMICA DE LA ACUMULACIÓN DE CAPACIDADES INOVADORAS: EVIDENCIAS DE EMPRESAS DE SOFTWARE EN RIO DE JANEIRO Y EN SÃO PAULO

\begin{abstract}
RESUMO
São escassos estudos sobre a dinâmica da acumulação de capacidades inovadoras. Este artigo examina o tema em oito empresas de software em São Paulo e Rio de Janeiro, encontrando: diferenças inter e intraempresariais em termos da direção e taxa de acumulação de capacidade para funções tecnológicas específicas; acúmulo de capacidade tecnológica mais rápido em empresas mais jovens; e decréscimo das taxas de acumulação tecnológica à medida que as empresas se aproximam de níveis mais inovadores de capacidades, demonstrando a potencialidade para aceleração do processo. Tais evidências são relevantes para o entendimento da acumulação tecnológica e fornecem uma noção do tempo necessário para se obterem benefícios de esforços de aprendizagem e construção de capacidade inovadora.
\end{abstract}

PALAVRAS-CHAVE Capacidade tecnológica, empresas de software, acumulação tecnológica, dinâmica de inovação, competitividade.

Eduardo C. Miranda dudamiß@uol.com.br

Gerente de Teste de Software da Microsoft Brasil - São Paulo - SP, Brasil

Paulo N. Figueiredo paulo.figueiredo@fgv.br

Professor da Escola Brasileira de Administração Pública e de Empresas, Fundação Getulio Vargas - Rio de Janeiro - RJ, Brasil

Recebido em 26.12.2007. Aprovado em 21.12.2009

Avaliado pelo sistema double blind review. Editor Científico: Tales Andreassi

\begin{abstract}
There still is a scarcity of studies examining the dynamics of the accumulation of innovative capabilities. This paper examines such issue in eight software companies in São Paulo and Rio de Janeiro, finding that: there were inter and intra-company differences in terms of speeds of capability accumulation for specific technological functions; younger companies have accumulated capabilities more rapidly; speeds of capability tended to decrease as companies accumulated more innovative levels of capabilities, offering a prospect for the acceleration of the innovation process. Such evidence is to deepen our understanding of the firm-level technological accumulation process, = and provide some notion of the time needed to obtain the benefits from efforts on learning and innovative capability building.
\end{abstract}

KEYWORDS Technological capability, software companies, technological accumulation, innovation dynamics, competitiveness.

RESUMEN Son escasos los estudios que examinan la dinámica de la acumulación de capacidades innovadoras. Este artículo examinó ese tema en ocho empresas de software en São Paulo y Rio de Janeiro, y encontró: diferencias inter e intraempresariales en términos de dirección y tasas de acumulación de capacidad para funciones tecnológicas específicas; acumulación de capacidad tecnológica más rápida en empresas más jóvenes; disminución de las tasas de acumulación tecnológica a medida que las empresas se aproximan a niveles más innovadores de capacidades, lo que demuestra potencialidad para aceleración del proceso. Tales evidencias son relevantes para el entendimiento del proceso de acumulación tecnológica y ofrecen una noción del tiempo necesario para obtener beneficios de esfuerzos de aprendizaje y construcción de capacidad innovadora.

PALAVRAS CLAVE Capacidad tecnológica, empresas de software, acumulación tecnológica, dinámica de innovación, competitividad. 


\section{INTRODUÇÃo}

Durante a década de 1970, diversas empresas no Japão, na Coreia do Sul e em Taiwan alcançaram a fronteira tecnológica internacional, não somente em termos de produção, mas principalmente no que se refere às capacidades tecnológicas inovadoras. Porém, a visão que prevalecia àquela época, em relação às empresas de países em desenvolvimento, era a de que estas estavam passivamente envolvidas somente na seleção e na adoção de tecnologias desenvolvidas em economias industrializadas. Assim, qualquer preocupação com o desenvolvimento de capacidades tecnológicas criativas em empresas de economias em desenvolvimento e emergentes era considerada irrelevante. Esse quadro era agravado pela assim chamada perspectiva da "dependência tecnológica" que tinha sido trazida da década de 1950. Segundo tal abordagem, havia uma falha generalizada em internalizar o processo de inovação em empresas e setores industriais na América Latina. Ou seja, segundo a tese da dependência, contrariamente às trajetórias de acumulação tecnológica inovadora dos países centrais, o processo de desenvolvimento tecnológico na América Latina estaria designado a ser permanentemente truncado.

A partir do início da década de 1970, o pessimismo e o negativismo tecnológicos emanados pela perspectiva da dependência foram desafiados por um conjunto pioneiro de estudos empíricos, os quais adotaram uma perspectiva dinâmica da tecnologia nas empresas da América Latina e, posteriormente, na Ásia. Tais estudos passaram a examinar os vários mecanismos pelos quais as empresas adquiriram o conhecimento técnico para acumular - ou falharam em acumular - suas capacidades tecnológicas inovadoras ao longo do tempo. Nesse sentido, esses estudos serviram de base para a emergência, a partir do início da década de 1990, de uma nova geração de estudos sobre o desenvolvimento de capacidades tecnológicas inovadoras no contexto de países em desenvolvimento (HOBDAY, 1995; KIM, 1997; DUTRÉNIT, 2000; ARIFFIN, 2000; FIGUEIREDO, 2001; CHOUNG, HWANG e YANG, 2006).

Alguns dos estudos dessa nova geração (ARIFFIN, 2000; FIGUEIREDO, 2001; TACLA e FIGUEIREDO, 2006) buscaram resgatar a perspectiva dinâmica dos pioneiros estudos da década de 1970, dando especial atenção ao tempo (timing) ou velocidade do processo de acumulação tecnológica; ou seja, ao tempo (medida em número de anos) que cada empresa leva para mover-se através de diferentes níveis de capacidade tecnológica. O entendimento do real processo de acumulação tecnológica, principalmente no tocante às empresas e setores industriais, é de fundamental importância no contexto de economias em desenvolvimento, pois para que estas alcancem a fronteira tecnológica é necessário que acelerem o processo de acumulação tecnológica a uma taxa normalmente mais rápida do que a observada em empresas de economias altamente industrializadas (BELL e PAVITT, 1995; FIGUEIREDO, 2001). Tal entendimento, por sua vez, apresenta igual relevância para gestores empresariais e governamentais que necessitam ter uma noção concreta do tempo necessário para se obter os benefícios de esforços em desenvolvimento de capacidade tecnológica inovadora (BELL, 2006). A despeito da importância do tema, o tratamento da velocidade ou dinâmica em estudos de inovação tem sido curiosamente negligenciado. Apesar de alguns termos, como dinâmica e mudança, aparecerem com frequência em estudos acadêmicos, estes são de fato estáticos, uma vez que captam apenas um ponto no tempo ou o momento atual. Por isso, acadêmicos deixam de oferecer respostas e explicações importantes às questões normalmente feitas por gestores empresariais e governamentais referentes ao tempo para alcançar certo nível tecnológico ou ao tempo que se tem de esperar para alcançar certo estágio tecnológico e com isso aprimorar seu desempenho competitivo.

Este artigo busca oferecer uma pequena contribuição nessa direção. Nessa perspectiva, examina a direção e a taxa (ou velocidade) de acumulação de capacidades tecnológicas em uma amostra de oito empresas de software no Rio de Janeiro e em São Paulo, durante o período de 1990 a 2005.

Sua estrutura comporta seis seções além desta introdução. Apresenta-se inicialmente uma breve revisão de estudos realizados na indústria de software. A base conceitual do estudo é trazida em seguida. Seu contexto empírico compõe a seção seguinte. Depois, são abordados os principais aspectos do desenho e método do estudo. A seção que vem logo depois contém seus principais resultados. Por fim, são apresentadas as conclusões e recomendações do artigo.

\section{ANTECEDENTES DO ESTUDO}

\section{Velocidade da acumulação tecnológica: uma preocupação antiga}

A velocidade ou taxa de mudança tecnológica, associada ao progresso econômico, tem sido investigada das mais diferentes maneiras e de diversas perspectivas ao longo do tempo, desde Adam Smith e Karl Marx. Nas últimas décadas, essa questão vem sendo examinada sistema- 
ticamente, tanto no âmbito das sociedades e de países (SCHUMPETER, 1942; LANDES, 1969; NELSON, 1981; ROSENBERG, 1982; FREEMAN, 1982) como no nível de indústrias específicas (ROSENBERG, 1963; MOWERY e ROSENBERG, 1982). No entanto, tais estudos têm sido focados na experiência dos países contemporâneos industrializados. Apesar de algumas exceções relativas ao contexto da industrialização recente (GERSCHENKRON, 1962; STRASSMAN, 1963; ROSENBERG, 1982; ROSENBERG e FRISCHTAK, 1985; AMSDEN, 2000) a questão da mudança tecnológica entre empresas no contexto dos países em desenvolvimento permaneceu inexplorada até, pelo menos, o início da década de 1970, como será comentado na próxima seção.

Enquanto alguns pesquisadores focaram a taxa de determinadas inovações tecnológicas, observada em empresas e indústrias (GRILICHES, 1957; MANSFIELD, 1961; ROGERS, 1983) outros seguiram investigando essas questões sob condições de racionalidade limitada e assimetria de conhecimento, incertezas e cumulatividade (NELSON, 1968; NELSON e WINTER, 1982; PAVITT, 1984; DOSI, 1988; MALERBA, 1992, 2005).

Seus modelos de análise e evidências proporcionaram o devido suporte para outros estudos relativos à taxa de mudança tecnológica no nível das indústrias e, em certa medida, no nível das empresas (ABERNATHY e CLARK, 1985; ANDERSON e TUSHMAN, 1990; HENDERSON e CLARK, 1990; CHRISTENSEN, 1992). Ainda nesse âmbito, outros estudos focaram essas questões com base nas estatísticas de patentes e pesquisas de inovação (PATEL e PAVITT, 1997; ARCHIBUGI e PIANTA, 1995). Contudo, apesar da enorme contribuição de tais estudos no sentido do avanço ou do entendimento da dinâmica das mudanças tecnológicas, eles ainda deixam a desejar quando se trata de enriquecer nosso conhecimento sobre o processo de desenvolvimento tecnológico entre as empresas de economia emergente.

Embora esses estudos foquem a questão da mudança na tecnologia e em organizações, não abordam os processos de acumulação de estoque de capacidade em nível de empresas ao longo do tempo. Em vez disso, focam a utilização, na exploração, na distribuição e na codificação do conhecimento inovador que já existe na empresa, seja na mentalidade das pessoas ou nas rotinas organizacionais. Com base em uma análise de tudo o que as empresas conhecem atualmente em termos de atividades tecnológicas e como elas impulsionam a fronteira tecnológica, esses estudos raramente nos dizem como essas empresas fazem para acumular o conhecimento tecnológico. Entretanto, as empresas de economia emergente normalmente tendem para os negócios voltados para a tecnologia que elas adquiriram das empresas originárias de economias industrializadas. É muito comum as empresas de economia emergente não terem o mínimo de capacidade técnica, tampouco conhecimento básico durante o processo inicial. Ademais, as empresas de economia emergente são frequentemente deslocadas das suas origens internacionais, onde fica a base da sua tecnologia - como os centros de Pesquisa e Desenvolvimento (P\&D) e as universidades e também dos principais nichos de mercado que elas pretendem atender (HOBDAY, 1995, 2003). Para se tornarem competitivas e se manterem atualizadas nas questões tecnológicas, essas empresas têm de se engajar em processos de aprendizado que possibilitem a construção de suas próprias capacidades, de modo a viabilizar a condução de atividades inovadoras de forma independente.

O segundo problema com a maioria dos estudos já realizados é relativo à mensuração das capacidades tecnológicas. Na maior parte desses estudos, em nível de empresas e de indústrias, as capacidades tecnológicas são mensuradas com base nos gastos das empresas na área de Pesquisa e Desenvolvimento, no gasto bruto em Pesquisa e Desenvolvimento, nas qualificações individuais, nos investimentos em recursos humanos na área de Pesquisa e Desenvolvimento, nas estatísticas de patentes dos EUA e nas publicações de artigos científicos. Uma combinação de estatísticas baseadas em P\&D, patentes, educação, ciência e recursos humanos é frequentemente utilizada para quantificar capacidades tecnológicas. Tais medições são utilizadas para agregar análises de desempenho industrial e/ou tecnológico, mesmo nos países desenvolvidos. No entanto, há situações em que algumas dessas formas de mensuração têm limitações ou são menos relevantes (LALL, 1990, 1992; BELL e PAVITT, 1993, 1995; ARIFFIN e BELL, 1999; ARIFFIN, 2000; HOBDAY, 2003; ARIFFIN e FIGUEIREDO, 2004). Em primeiro lugar, como apontado por Ariffin (2000) as estatísticas de P\&D e de patentes somente prevalecem em países industrializados (por exemplo, EUA, Japão e alguns países da Europa, como o Reino Unido e a Alemanha), onde as empresas já desenvolveram sua capacidade de inovação tecnológica em níveis tão avançados a ponto de estarem aptas a conduzirem P\&D e a produzirem patentes internacionais.

Em segundo lugar, a aplicabilidade de tais indicadores geralmente baseados em pesquisas convencionais - não capta as atividades inovadoras não relacionadas à área de Pesquisa e Desenvolvimento que são desenvolvidas nas diversas unidades das empresas (BELL e PAVITT, 1995). Ou seja, tais indicadores - e as análises agregadas geradas por eles - não levam em consideração o tecido organizacional em que a capacidade tecnológica é gerada e desen- 
volvida (FIGUEIREDO, 2001). A aplicabilidade exclusiva dos indicadores às empresas de economia emergente não somente pode levar a uma interpretação limitada da realidade industrial, como também excluir diversas empresas e indústrias de economia emergente do debate internacional e das análises do desenvolvimento tecnológico e da inovação industrial. Além disso, a ênfase exagerada nos indicadores de Pesquisa e Desenvolvimento e de patentes parece ofuscar a relevância das capacidades das áreas técnicas, de engenharia e de design, que são muito importantes no processo de atualização (BELL, 1984; BELL e PAVITT, 1993, 1995; BELL e outros, 1995).

Especificamente, os estudos estáticos (snap-shot) e as pesquisas de inovação agregadas não reúnem evidências de capacidades de inovação nos níveis básico, intermediário e/ou avançado para as mais diferentes funções tecnológicas, tais como gestão de projetos, organização de processos e de produção, foco nos produtos e serviços e atividades relacionadas aos equipamentos. Estes, contudo, são os níveis e tipos de capacidade tecnológica que prevalecem nas empresas e indústrias emergentes. Particularmente, os níveis intermediários de capacidade são pré-requisitos para que sejam obtidas capacidades baseadas em pesquisa e patentes no nível da fronteira internacional do conhecimento (BELL e PAVITT, 1993, 1995; BELL e outros, 1995; ARIFFIN, 2000; BELL, 2006).

Por isso, é importante ter uma ideia concreta da velocidade na qual as empresas e indústrias se movimentam em direção aos altos níveis de capacidade tecnológica (partindo do sistema baseado em produção para os diferentes níveis de atividades inovadoras) para que se possa entender o processo de acumulação de capacidades tecnológicas nas empresas e indústrias dos países em desenvolvimento. Como mencionado por Bell (2006), as evidências e as análises das velocidades de capacidade de desenvolvimento das empresas são importantes para embasar o processo decisório em áreas como a de gestão estratégica nas empresas, gestão de programas relacionados ao governo para apoiar o desenvolvimento tecnológico de indústrias e de empresas e de desenvolvimento de políticas de longo prazo voltadas para as estratégias tecnológicas e para o crescimento industrial. Ademais, conforme mencionado por Figueiredo (2001, 2008) e Ariffin (2000), as descobertas relativas à velocidade de acumulação de capacidade são importantes para fornecer aos executivos corporativos e gestores públicos uma noção do tempo (timing) necessário para materializar alguns dos retornos, referentes à construção de capacidade inovadora, que sejam esperados a partir dos seus esforços ao longo do tempo. No entanto, dois esclarecimentos são importantes nesse momento.
Em primeiro lugar, não estamos sugerindo que a evidência retrospectiva de taxas de capacidade de acumulação poderia servir de base ou de modelo para estratégias tecnológicas atuais ou futuras. Conforme sugerem Gerschenkron (1962) e Hobday (2003), os padrões e as taxas de industrialização do passado não podem orientar futuras políticas de industrialização. Assim, ao contrário de Chang (2003, 2007), rejeitamos as perspectivas que defendem que as estratégias industriais, baseadas em medidas cambiais ou proteção a indústrias nascentes locais utilizadas no passado por economias industrializadas, sejam simplesmente replicadas atualmente em economias emergentes (ver FIGUEIREDO, 2004).

De um lado, essa visão parece negligenciar as limitações das estratégias protecionistas (por exemplo, políticas de indústrias nascentes) como medidas de atualização; por outro lado, parece não observar o fato de que os processos de aprendizagem tecnológica e de atualização são fundamentalmente diferentes nos séculos XIX, XX e XXI. As empresas de economia emergente apresentam condições diferentes das mais antigas, seja no âmbito institucional, político, científico ou mercadológico.

Em segundo lugar, quando focamos a capacidade de acumulação das taxas das empresas de economia emergente, é importante considerarmos a velocidade do avanço da fronteira tecnológica internacional. Uma possível implicação é que a empresa pode nunca alcançar a fronteira tecnológica (ou pode levar tempo demais para fazê-lo) se a sua taxa de construção de capacidade for mais lenta do que a da fronteira. No entanto, também é fundamental considerar que o processo de desenvolvimento das empresas mais recentes não é uma corrida sobre uma pista fixa, portanto alcançar a fronteira tecnológica não é simplesmente uma questão de velocidade relativa. Ou seja, apesar de o fator velocidade ser relevante, existem exemplos de sucesso em uma nova direção e da emergência de uma descontinuidade radical que cria oportunidades para empresas de economias emergentes (PEREZ, 1983; PEREZ e SOETE, 1988). Ademais, a própria fronteira tecnológica é fluida. Isso, por sua vez, possibilita que empresas de economias emergentes "ultrapassem" empresas líderes de economias industrializadas.

\section{Velocidade de acumulação tecnológica no contexto de economias emergentes}

Em meados da década de 1970, houve uma série de estudos empíricos pioneiros que adotou uma perspectiva dinâmica da tecnologia em empresas da América Latina e da Ásia, deixando de lado a questão estática da escolha a partir de determinado conjunto de técnicas (STEWART 
e JAMES, 1982). Esses estudos abordam diversos mecanismos por meio dos quais as empresas adquiriram conhecimento tecnológico para construir - ou não - suas capacidades tecnológicas inovadoras através do tempo (KATZ, 1976, 1987; DAHLMAN e FONSECA, 1978; BELL e outros, 1995; LALL, 1987; entre outros). Tais estudos deram uma enorme contribuição para o entendimento da natureza e da dinâmica do processo de aprendizado tecnológico dentro das empresas mais recentes. Entretanto, o foco de análise foi extremamente centrado nos aspectos técnicos das capacidades tecnológicas que não examinaram propriamente as dimensões organizacionais do aprendizado e da construção do conhecimento.

Apesar disso, essa série de estudos começou a desenvolver generalizações sobre o direcionamento e a taxa de capacidade de acumulação tecnológica das empresas e, especialmente, o papel dos mecanismos de aprendizagem (principalmente a aquisição de conhecimento advindo de fora da empresa) nas trajetórias das empresas influentes e também nas implicações do desenvolvimento da capacidade nas unidades das empresas. Especificamente, esses estudos descobriram um conjunto de mecanismos de aprendizagem que se revelaram em meio à acumulação de capacidades tecnológicas nessas unidades. Esses aspectos foram analisados posteriormente no estudo clássico de Bell (1984), no qual é feita uma distinção entre os mecanismos de aprendizagem baseados na prática e aqueles relacionados às mudanças.

Em sua maioria, foram examinadas trajetórias de sucesso de acumulação de capacidades tecnológicas de empresas em diferentes indústrias e em diversos países, especialmente na América Latina e, até certo ponto, na Ásia. De maneira geral, esses estudos traçaram os processos de transição através de diferentes estágios de acumulação de capacidades tecnológicas das empresas em períodos que variaram entre 15 e 25 anos. No entanto, baseando-se em contraevidências, Bell e outros (1995) examinam um caso mal-sucedido de três empresas de galvanização de aço da Tailândia: em um período de 13 anos, foi observada uma total ausência de capacidade tecnológica inovadora. Em vez disso, foi encontrado "um processo operacional extremamente básico e rudimentar" (p. 152) que dava um retorno de crescimento produtivo estagnado ou negativo. Tal desempenho tecnológico é associado, de um lado, à preponderância dos mecanismos de aprendizagem baseados na prática e, por outro, a uma política de industrialização profundamente baseada em um regime protecionista e de substituição da importação.

O mérito dessa série de estudos é ter evidenciado a relevância do comprometimento intraempresarial com o pro- cesso de geração de conhecimento tecnológico para criar capacidades tecnológicas nas próprias unidades (KATZ, 1987). Esses trabalhos também demonstraram que a acumulação de tais capacidades é, no mínimo, condição necessária para uma mudança tecnológica significativa, especialmente no longo prazo (BELL, 1984). No entanto, como esses estudos estavam focados em unidades de empresas isoladamente, não oferecem uma análise comparativa entre as trajetórias de acumulação tecnológica das empresas. Apesar de os estudos abordarem os mecanismos de aprendizagem internos, o foco maior foi na aquisição de conhecimento de fontes externas. Consequentemente, pouco foi explorado sobre a base organizacional para a conversão do conhecimento tácito em capacidades para a empresa.

Somente em meados da década de 1990, começaram a surgir na literatura novos estudos empíricos sobre a construção do aprendizado e das capacidades tecnológicas de empresas de industrialização recente. Esses estudos eram, em contrapartida, influenciados pela difusão de estudos referentes às capacidades tecnológicas específicas da empresa e aos processos de aprendizagem como principais responsáveis pelo desempenho competitivo nas empresas altamente inovadoras dos países industrializados.

Hobday (1995) empenha-se em reavaliar o processo de construção de capacidades tecnológicas e os processos subjacentes de aprendizagem nas empresas de economia emergente através do estudo da trajetória de desenvolvimento de capacidade em algumas empresas do Leste Asiático. Tal estudo investigou detalhadamente as trajetórias tecnológicas das empresas durante décadas. Todavia, o estudo generalizou suas conclusões nas taxas de construção tecnológica das empresas, organizadas em décadas, entre as empresas e indústrias da região estudada. Dessa maneira, o estudo não observou as nuanças e as particularidades das taxas de desenvolvimento de capacidade de cada uma das empresas e indústrias especificamente.

Esforços de pesquisas semelhantes, mas sem a mesma preocupação com o tempo de construção de capacidade, foram reportados em Kim (1997) com base em uma grande quantidade de evidências de empresas sul-coreanas. A partir dessa estratégia de pesquisa, porém também explorando as implicações negativas do processo de aprendizagem, Dutrénit $(1998,2000)$ e Hwang (1998) trazem avanços significativos para o entendimento do processo de acumulação de capacidade das empresas de industrialização recente no longo prazo. De um lado, esses estudos se empenharam em resgatar boa parte da abordagem dinâmica dos estudos pioneiros da década de 1970 liderados ou influenciados por Jorge Katz e seus colegas. Por outro lado, eles não examinaram a taxa de construção tecnológi- 
ca de maneira sistemática. Apesar de estudos subsequentes terem surgido nos últimos anos, estes não têm um tratamento empírico explícito, deliberado e sistemático da taxa de construção de capacidade tecnológica. Por exemplo, Amsden e Tschang (2003) empenharam-se em examinar o desenvolvimento de capacidades em Desenvolvimento e Pesquisa em Singapura. Embora muito esclarecedor, o estudo não traz uma noção empírica clara das escalas de tempo envolvidas no que se refere à mudança - de um desenvolvimento exploratório e avançado para uma pesquisa aplicada. Além disso, o estudo de Yu (2005) sobre as trajetórias tecnológicas das empresas manufatureiras fornece apenas evidências fragmentadas das escalas de tempo envolvidas no processo de acumulação tecnológica das empresas.

O estudo reportado em Choung, Hwang e Yang (2006) empenhou-se em examinar a "coevolução" da tecnologia e das instituições na indústria de informação e tecnologia da Coreia do Sul, mas oferece ao leitor um tratamento implícito das escalas de tempo envolvidas em tal processo. Com relação a esse assunto, Liu, Quian e Cheng (2006) focam a "construção de capacidade tecnológica" no estudo de cinco empresas chinesas de manufatura baseadas em tecnologia de larga escala; mas, como em Choung, Hwang e Yang (2006), o problema com a maioria desses estudos é que eles não mensuram o tempo despendido pelas empresas para realmente construir diferentes tipos e níveis de capacidades. De fato, conforme observado por Bell (2006), o problema com a maioria desses estudos é que eles tendem a deixar que o leitor calcule e conclua o tempo envolvido no processo de desenvolvimento de capacidade das firmas e indústrias estudadas. Apesar de haver algumas exceções (HOBDAY, 1995) mesmo a partir da década de 1990, o campo de pesquisa na área de inovação tecnológica no contexto da industrialização recente não tem tratado a questão da taxa de acumulação de capacidade de maneira devidamente explícita e sistemática. Em uma crítica abrangente sobre a maneira pela qual a literatura sobre a industrialização recente tem tratado a dinâmica da acumulação de capacidade nas empresas e indústrias dos países em desenvolvimento, Martin Bell (2006, p. 30) menciona:

De fato, mesmo cerca de 20 anos depois do término do "programa de Katz" no início dos anos 80, nós ainda não temos praticamente ideia nenhuma de quanto tempo se leva para se movimentar dentro dos estágios, ainda que ilustrativos, de acumulação de capacidade em qualquer circunstância de industrialização recente. A respeito do tempo que se leva normalmente para se movimentar dentro de uma sequência de estágios em uma situação em particular, ainda somos incapazes de ir muito além da vaga generalidade sugerida há quase 20 anos por Dahlman e colegas: um certo número de "décadas, não anos". Consequentemente, nós permanecemos muito distantes de poder oferecer qualquer detalhamento de como e por que tais períodos de tempo variam em diferentes circunstâncias.

No entanto, alguns esforços de pesquisa têm sido feitos nos últimos anos para abordar as taxas de acumulação de capacidade em nível de empresas. Como comentado por Bell (2006, p. 30),

essas exceções, e talvez até outras que desconheço, não contribuem muito para iluminar a nossa imensa ignorância sobre a taxa de aprendizado nas empresas de industrialização recente. No entanto, elas servem para ilustrar a maneira pela qual, se considerarmos seriamente as métricas ligadas a tempo do aprendizado de tais empresas, poderíamos começar a levantar questões interessantes e úteis sobre a gestão da aprendizagem em empresas, ou sobre o significado das várias influências das trajetórias de desenvolvimento no nível das indústrias.

À luz dos argumentos trazidos por Bell (2006), este artigo oferece uma breve discussão baseada em evidências de alguns dos estudos recentes que abordam a questão das taxas de construção de capacidade das empresas recentemente industrializadas. Por meio da compilação das conclusões de alguns desses estudos, este artigo visa contribuir para a expansão da discussão desenvolvida em Bell (2006), assim como rever seus méritos, suas limitações e os nossos aprendizados originados desses estudos. Isso deve, em contrapartida, contribuir para estimular cada vez mais a pesquisa e para fortalecer e aprofundar esse campo de estudo.

\section{BASE CONCEITUAL DO ESTUDO}

\section{Capacidade tecnológica e inovação: o que são e como medi-las?}

Existem diversas definições de capacidades tecnológicas, particularmente no contexto de países em desenvolvimento, como, por exemplo, em Katz (1976), Bell (1984), Lall (1982, 1992), Dahlman e Westphal (1982) e Kim (1997), já discutidas em profundidade anteriormente (DUTRÉNIT, 2000; FIGUEIREDO, 2001). Neste artigo, capacidade tecnológica é definida como os recursos necessários (ou estoque de conhecimento, portanto ativo 
cognitivo) para gerar e gerenciar atividades inovadoras em produtos, processos e organização da produção, sistemas organizacionais, equipamentos e engenharia de projetos; em outras palavras, mudança tecnológica. Esses recursos estão incorporados não apenas nos indivíduos (habilidades, experiências, qualificações formais) mas, principalmente, no sistema organizacional, rotinas e procedimentos da empresa (BELL e PAVITT, 1995; FIGUEIREDO, 2001). É por meio da capacidade tecnológica que empresas realizam atividades de produção e de inovação.Definimos inovação como a implementação de ideias criativas dentro de uma organização. Dessa maneira, a criatividade de indivíduos e grupos é um ponto de partida para a inovação. A criatividade, portanto, é uma condição necessária, mas não suficiente para a inovação. A existência de inovação envolve mais do que a junção de várias ideias criativas. Ideias devem ser colocadas em prática para se fazer uma diferença genuína, como, por exemplo, a implementação de uma nova rotina organizacional, de uma nova técnica de produção, ou de nova maneira de prestação de um serviço. Desse modo, a criatividade deve ser mostrada por pessoas; porém, a inovação ocorre apenas em um contexto organizacional (AMABILE, 1996).

De fato, a perspectiva de Schumpeter (1942) sobre inovação vai muito além da mudança tecnológica em sentido estrito. Envolve a "condução de novas combinações" interpretada de maneira ampla. Esse conceito cobre os seguintes casos: (i) a introdução de um novo bem ou serviço - com o qual os consumidores ainda não estão familiarizados - ou uma nova característica em um produto; (ii) a introdução de um novo método de produção que ainda não foi testado em certa linha de produção e não tem validade científica; (iii) a abertura de um novo mercado, ainda inédito para a empresa, mesmo que esse mercado não tenha existido antes; e (iv) a conquista de uma nova fonte de matéria-prima ou produtos semimanufaturados, independente de essa fonte já existir ou ter sido recentemente criada.

Um dos critérios-chave para o sucesso de inovações (tecnológicas) é o sucesso comercial em vez de técnico. Uma inovação bem-sucedida é aquela que retorna o investimento original de seu desenvolvimento com acréscimos; o que exige que um mercado suficientemente grande para a inovação possa ser desenvolvido. Finalmente, inovação deve ser entendida como processo, e não como eventos isolados.

Nesse sentido, considerando as características das empresas inseridas em economias emergentes, a dinâmica e a ampla cobertura das trajetórias de acumulação de capacidade das empresas - das baseadas em produção aos níveis progressivamente inovadores - a perspectiva sobre inovação aqui adotada não pode estar restringida à prevalente ideia da introdução de produtos de ponta, serviços e processos baseados na exploração da existente capacidade alicerçada em pesquisa, na fronteira tecnológica mundial. Assim, nos embasamos em uma ampla ideia de inovação, que abrange a implementação de mudanças em produtos/ serviços, processos, e sistemas organizacionais e gerenciais - da iniciação à adaptação menor para a avançada - que são novos no contexto local e não necessariamente novos para o mundo, bem como o desenho e o desenvolvimento de novos sistemas globais. Desse modo, a inovação consiste em um processo contínuo e não em simples episódios; esse processo envolve a resolução de problemas em torno de tipos diferentes de atividades e requerem estoques de capacidade e processos de aprendizagem específicos às empresas e a outros tipos de organização (NELSON e WINTER, 1982; DOSI, 1988). Tal processo é igualmente influenciado pela natureza do contexto institucional em que elas nascem e crescem (NELSON, 2007).

Essa abordagem da inovação está em linha com o Manual de Oslo (OECD, 2002) que tem mostrado distinções entre as inovações que são "novas à empresa", "novas ao mercado" e "novas para o mundo". Esse espetro de uma compreensiva perspectiva da inovação é bem capturado na definição fornecida por Dosi (1988, p. 251): "em um sentido essencial, inovação refere-se à busca, descoberta, experimentação, desenvolvimento, imitação, e adoção de novos processos de produção e novas configurações organizacionais."

Essa afirmação é importante para demonstrar que, quando se trata de inovação, a questão não é "ser ou não ser inovador", mas em que "grau" ou "estágio. Especificamente, a ideia "binária" de "empresa inovadora" ou "não inovadora" é limitada e equivocada. Essa perspectiva de inovação como um contínuo de atividades com crescentes graus de dificuldade e sofisticação é particularmente importante para compreendermos o processo de inovação em empresas que operam em países em desenvolvimento - economias emergentes; diferentemente de empresas que operam na fronteira de inovação, normalmente localizadas em países industrializados.

Um esclarecimento apropriado dessa perspectiva é particularmente importante para o contexto de empresas em economias de industrialização tardia: há indicações de que há diversos tipos de atividades não relacionados à pesquisa e desenvolvimento ( $\mathrm{P} \& \mathrm{D}$ ) realizados em diversos outros tipos de unidades organizacionais dentro de empresas inseridas em economias de industrialização tardia (BELL e PAVITT, 1993). Estas podem ser vistas como con- 
dições prévias para a realização de atividades inovadoras de níveis mais elevados, baseados, por exemplo, em P\&D e atividades da patenteLall (1982), Bell e Pavitt (1995) e Figueiredo (2001) propõem um modelo que, baseado em atividades, sugere que a acumulação das capacidades tecnológicas ocorre em "estágios" que evoluem de básicos para intermediários a complexos. Além disso, existe um conjunto mínimo dessas capacidades para que a empresa seja capaz de executar suas principais funções. Esse conjunto de capacidades deve amadurecer e evoluir para que a empresa atinja as capacidades necessárias para que seja inovadora. Para avaliar os níveis de acumulação de capacidades em cada uma das principais funções tecnológicas da empresa (ou setor), estas são dispostas em uma estrutura matricial que diferencia as atividades básicas de produção das atividades inovadoras. As colunas identificam as funções tecnológicas e as linhas os níveis de difi- culdade. Os níveis de capacidade são determinados pelas atividades que a empresa é capaz de exercer de maneira independente (LALL, 1982; FIGUEIREDO, 2001, 2004).

Para analisar as capacidades tecnológicas acumuladas nas empresas da amostra, foi criada uma matriz dispondo as funções tecnológicas em colunas e os seis níveis de complexidade em linhas. O Quadro 1 apresenta a métrica para medir níveis de capacidade adaptada ao contexto industrial tecnológico das empresas aqui estudadas. Para ser aplicada neste estudo, essa métrica foi adaptada, calibrada e validada com auxílio de especialistas do setor de software. $\mathrm{O}$ processo de adaptação e validação levou aproximadamente seis meses. Muito embora a métrica apresente os níveis de capacidades de forma linear, não se deve presumir que a acumulação destas seguirá essa linearidade.

Especificamente na indústria de software e eletrônicos, indicadores associados a P\&D e patentes têm sido usados

\section{Quadro 1 - Métrica para exame de capacidades tecnológicas em empresas de software}

\begin{tabular}{|c|c|c|c|c|}
\hline & $\begin{array}{c}\text { NIVEIS DE } \\
\text { CAPACIDADE }\end{array}$ & ENGENHARIA DE SOFTWARE & PRODUTOS E SERVIÇOS (A) & PROCESSOS \\
\hline \multirow{3}{*}{$\begin{array}{l}\text { 낀 } \\
\text { 음 } \\
\text { 음 }\end{array}$} & $\begin{array}{l}\text { Nível } 6 \\
\text { Inovação } \\
\text { Avançada } \\
\text { (próxima } \\
\text { à fronteira } \\
\text { internacional) }\end{array}$ & $\begin{array}{l}\text { Ferramentas próprias de engenha- } \\
\text { ria de software; integração com } \\
\text { ferramentas de outras áreas de } \\
\text { conhecimento, como Geo-posicio- } \\
\text { namento e Telecom; ferramentas } \\
\text { geradoras de código; e equipes } \\
\text { geograficamente distantes. }\end{array}$ & $\begin{array}{l}\text { Serviços de P\&D com tecnologias } \\
\text { e tendências de ponta, como grid } \\
\text { computing, convergência de mídias } \\
\text { e TV Digital [S]; e P\&D com tecno- } \\
\text { logias de ponta, visando ao lança- } \\
\text { mento de produtos inovadores e } \\
\text { difíceis de copiar [P]. }\end{array}$ & $\begin{array}{l}\text { Aprimoramento contínuo dos pro- } \\
\text { cessos, tanto a partir de avanços } \\
\text { incrementais nos processos exis- } \\
\text { tentes quanto a partir de novos } \\
\text { métodos e tecnologias. }\end{array}$ \\
\hline & $\begin{array}{l}\text { Nível } 5 \\
\text { Inovação } \\
\text { Intermediária }\end{array}$ & $\begin{array}{l}\text { Integração das ferramentas de en- } \\
\text { genharia; ferramentas automatiza- } \\
\text { das de inspeção de código e testes } \\
\text { de software; equipes multidiscipli- } \\
\text { nares integradas e ferramentas de } \\
\text { colaboração; técnicas de geração } \\
\text { de versões diárias; e frameworks } \\
\text { de desenvolvimento de software. }\end{array}$ & $\begin{array}{l}\text { Soluções de alto valor agregado e } \\
\text { alta complexidade e conhecimento } \\
\text { técnico e de negócios [S]; soluções } \\
\text { completas com integração e perso- } \\
\text { nalização de software corporativo } \\
\text { [S]; utilização de tecnologias de } \\
\text { ponta, como RFID (b); reconheci- } \\
\text { mento de voz, para criar produtos } \\
\text { capazes de gerar demanda [P]. }\end{array}$ & $\begin{array}{l}\text { Os processos controlados com mé- } \\
\text { tricas de qualidade. A estrutura da } \\
\text { empresas adaptada ao processo. } \\
\text { Automatização de etapas cruciais } \\
\text { do processo, como testes unitários } \\
\text { e controle de versão. }\end{array}$ \\
\hline & $\begin{array}{l}\text { Nível } 4 \\
\text { Inovação } \\
\text { Básica }\end{array}$ & $\begin{array}{l}\text { Adaptações das ferramentas de } \\
\text { engenharia; padronização das } \\
\text { práticas de teste e inspeção de } \\
\text { código; interação com fornecedo- } \\
\text { res, clientes e parceiros; criação e } \\
\text { controle de versões automatizadas; } \\
\text { técnicas avançadas de controle de } \\
\text { versão; e criação de biblioteca de } \\
\text { componentes. }\end{array}$ & $\begin{array}{l}\text { Soluções desenvolvidas com co- } \\
\text { nhecimento específico do negócio } \\
\text { do cliente [S]; } \\
\text { configuração e personalização de } \\
\text { softwares corporativos (ERP (c), } \\
\text { CRM (d)) [S]; evolução contínua } \\
\text { dos produtos (horizontal e verti- } \\
\text { cal) [P]; e novos produtos utilizan- } \\
\text { do conhecimento já adquirido em } \\
\text { produtos anteriores [P]. }\end{array}$ & $\begin{array}{l}\text { Gestão estratégica da qualidade; } \\
\text { obtenção de certificações (CMM, } \\
\text { ITIL (e) e CobIT (f)). Adaptação } \\
\text { dos processos às práticas sugeri- } \\
\text { das nessas certificações. Proces- } \\
\text { sos apoiados e controlados por } \\
\text { software. }\end{array}$ \\
\hline
\end{tabular}


como medidas da acumulação de capacidades tecnológicas nas empresas de países em desenvolvimento (Tessler e Barr, 1997; SOFTEX, 2002; AMSDEN e TSCHANG, 2003; Tschang, AMSDEN e SADAGOPAN, 2003). Amsden e Tschang (2003) estabelecem uma taxionomia para classificar as atividades de $P \& D$ em cinco estágios e relacionam essa classificação à maturidade das capacidades inovadoras nessas empresas. Em Tschang, Amsden e Sadagopan (2003) tal modelo, adaptado à realidade da indústria de software, é sugerido como um modelo de evolução de capacidades inovadoras, na medida em que as empresas passam a realizar P\&D mais avançados e alcançam novos níveis de capacidades inovadoras. Esses indicadores, no entanto, podem ser limitados em certas situações, principalmente se utilizados em países em desenvolvimento, conforme argumentam Lall (1982), Bell e Pavitt (1993, 1995), Dutrénit (2000), Ariffin (2000) e Figueiredo (2003, 2004, 2009).

Muitas empresas e setores de países em desenvolvimento não têm atividades relevantes de $P \& D$ e produção de patentes. Em empresas de menor porte, nem sempre existem estruturas formais de laboratórios de P\&D; todavia, atividades tecnológicas que acumulam capacidades podem ocorrer em outros departamentos de engenharia, qualidade e produção. Além das limitações acima citadas, referentes aos indicadores relacionados a atividades de P\&D, os estudos realizados em empresas de software em países emergentes têm se caracterizado por retratar as capacidades tecnológicas e as atividades de P\&D em um ponto do tempo; essa abordagem estática falha em estabelecer uma linha evolutiva do comportamento das capacidades tecnológicas. Dessa forma, as evidências empíricas desses estudos não corroboram com o modelo proposto, no qual as empresas evoluem em diferentes estágios de P\&D para adquirirem as capacidades inovadoras. No setor de Tecnologia da Informação e de Comunicação (TIC), a certificação conhecida como Capability Maturity Model (CMM), elaborada pelo Software Engineering Institute (SEI), é muitas vezes utilizada como medida de acumulação de capacidades tecnológicas. O modelo avalia a maturidade do processo de engenharia de software em uma empresa e o classifica em cinco níveis. Alguns estudos, como Tschang e Xue (2005) e SOFTEX (2002), utilizam as estatísticas de certificação CMM em um país como uma das medidas para avaliar o nível de acumulação de capacidades tecnológicas atingido pela sua indústria de software. Porém, como já argumentado em Baskerville e Pries-Heje (1999), SOFTEX (2002), Tschang, Amsden e Sadagopan (2003) e NASSCOM (2005), o CMM como indicador de acumulação de capacidades tecnológicas pode ter limitações em situações específicas.

Devido à sua origem, o CMM tem foco essencialmente na capacidade da empresa em cumprir prazos e garantir a qualidade final do produto gerado, subavaliando outras importantes capacidades tecnológicas necessárias para que uma empresa de software seja considerada inovadora. Por ter sido criado como uma série de boas práticas, visando grandes empresas, muitas vezes o custo de aplicá-lo em pequenas empresas é simplesmente proibitivo. Além disso, algumas empresas conseguem alcançar níveis de maturidade em processo e qualidade utilizando caminhos alternativos ao CMM. Atualmente, a indústria de software indiana é a que ostenta o maior número de empresas com CMM nível 5 no mundo. Entretanto, essa indústria ainda não atingiu níveis de capacidades inovadoras que a levassem à fronteira tecnológica do mercado. A estrutura do CMM, classificando as empresas em níveis de maturidade e avaliando a evolução das atividades tecnológicas desempenhadas pela empresa de forma linear, não é capaz de captar evoluções incrementais e não simétricas das capacidades tecnológicas, mas somente grandes evoluções, simétricas, de um nível para o próximo. Por isso, o CMM como indicador para o exame de capacidades tecnológicas em empresas de software não é considerado adequado aos objetivos desta pesquisa. A utilização deste será apenas complementar ao modelo utilizado.

\section{CONTEXTO EMPÍRICO DO ESTUDO}

O mercado brasileiro de software se posiciona atualmente como o $12^{\circ}$ do mundo, tendo movimentado 15 bilhões de dólares, equivalente a 0,96\% do PIB brasileiro em 2008 (SOFTEX, 2008). Grande parte desse mercado é dominada por países que já se consolidaram como players, como Irlanda, Israel e Índia. No entanto, tanto o Brasil como a China vêm sendo apontados como possíveis novos concorrentes. Nos últimos anos, o governo brasileiro tem laçado uma série de programas de apoio à indústria e à exportação de software.

A iniciativa privada também se organiza com a criação de entidades, como a Associação Brasileira das Empresas de Software e Serviços para Exportação (BRASSCOM) e o Núcleo para Exportação de Tecnologia (NEXT), que buscam fortalecer a imagem das empresas brasileiras de software no exterior e auxiliá-las com a terceirização das atividades administrativas relacionadas à exportação. Grande parte dessas iniciativas, porém, busca soluções para problemas e dificuldades externas à empresa, relacionados principalmente a fatores econômicos e administrativos, como financiamento e desburocratização do processo de exportação. Para competirem no mercado interno e externo, as 
empresas de software necessitam ser competitivas frente aos seus principais concorrentes. A pesquisa apresentada em SOFTEX (2005), realizada com 300 empresas exportadoras de software, indica entre os fatores críticos para a competitividade: qualidade; recursos humanos tecnicamente capacitados; pontualidade; e capacidade de inovação. Desse modo, a acumulação de capacidades tecnológicas nas empresas se mostra primordial para o fortalecimento da indústria de software brasileira e o cumprimento dos objetivos desafiadores do governo brasileiro e das empresas.

\section{DESENHO E MÉTODO DO ESTUDO}

O estudo que deu origem a este artigo foi desenhado para examinar o aspecto da dinâmica do processo de acumulação de capacidades tecnológicas, em nível de empre- sas. Uma vez que estamos preocupados em aprofundar o entendimento sobre a natureza desse processo, ou seja, objetivamos aqui gerar uma generalização analítica, o estudo foi desenhado à base de estudo de caso (PATTON, 2003). Considerando que buscamos explorar a heterogeneidade inter e intra-empresarial no que diz respeito à dinâmica da acumulação tecnológica, nosso estudo se baseia em estudo de casos múltiplos. Para isso, foi deliberadamente selecionado um conjunto de empresas do setor de software nas duas maiores capitais brasileiras, Rio de Janeiro e São Paulo, conforme apresentadas no Quadro 2. O critério de seleção baseou-se na ideia de explorar a diversidade da dinâmica do processo de acumulação de capacidades tecnológicas.

A pesquisa baseou-se em evidências qualitativas e quantitativas de primeira mão colhidas pessoalmente por meio extensivos trabalhos de campo. Para obtermos alta

Quadro 2 - Modelo para descrição de capacidades tecnológicas em empresas de software

\begin{tabular}{|c|c|c|c|}
\hline & $\begin{array}{l}\text { NIVEIS DE } \\
\text { CAPACIDADE }\end{array}$ & ENGENHARIA DE SOFTWARE & PRODUTOS E SERVIÇOS \\
\hline \multirow{3}{*}{ 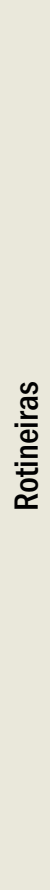 } & $\begin{array}{l}\text { Nível } 3 \\
\text { Operação } \\
\text { Avançada } \\
\text { (world-class) }\end{array}$ & $\begin{array}{l}\text { Padronização e documentação das } \\
\text { práticas de engenharia de software. } \\
\text { Utilização de componente de ter- } \\
\text { ceiros. Técnicas incipientes de re- } \\
\text { aproveitamento de código; controle } \\
\text { de versão de código-fonte. }\end{array}$ & $\begin{array}{l}\text { Realiza análise, definição e es- } \\
\text { pecificação dos requisitos para o } \\
\text { cliente [S]; implantação de softwa- } \\
\text { res corporativos (ERP, CRM) [S]; e } \\
\text { reengenharia de produtos, porém } \\
\text { agregando funcionalidades [P]. }\end{array}$ \\
\hline & $\begin{array}{l}\text { Nível } 2 \\
\text { Operação } \\
\text { Intermediária }\end{array}$ & $\begin{array}{l}\text { Melhor utilização das ferramentas } \\
\text { de engenharia de software; forma- } \\
\text { lização incipiente das práticas de } \\
\text { engenharia de software; backup } \\
\text { centralizado do código-fonte; e pe- } \\
\text { quenos exemplos de código fonte } \\
\text { para reaproveitamento. }\end{array}$ & $\begin{array}{l}\text { Atende as especificações funcio- } \\
\text { nais do cliente, realizando a es- } \\
\text { pecificação técnica [S]; projetos } \\
\text { completos e maiores [S]; e reen- } \\
\text { genharia de produtos já existentes } \\
\text { no mercado [P]. }\end{array}$ \\
\hline & $\begin{array}{l}\text { Nível } 1 \\
\text { Operação } \\
\text { Básica }\end{array}$ & $\begin{array}{l}\text { Utilização de ferramentas de en- } \\
\text { genharia de software de forma in- } \\
\text { cipiente; e práticas de engenharia } \\
\text { de software ad hoc. }\end{array}$ & $\begin{array}{l}\text { Replicação de especificações fun- } \\
\text { cionais e técnicas determinadas } \\
\text { pelos clientes [S]; pequenas solu- } \\
\text { ções ou partes de projetos [S]; e } \\
\text { manutenção de soluções já exis- } \\
\text { tentes [S]. }\end{array}$ \\
\hline
\end{tabular}

\section{PROCESSOS}

Padronização do processo de engenharia de software. Capacitação em metodologias de gestão de processos. Técnicas de controle de qualidade incipientes.

Padronização básica dos processos, as grandes etapas do processo passam a ser executadas de forma semelhante, porém ainda sem formalização e documentação necessária.

Processos operacionais não formalizados. Cada projeto segue um processo diferente.

Fonte: Adaptado de Figueiredo (2003).

Notas: (a) Cada atividade da função tecnológica produtos e serviços está marcada com um indicador do modelo de negócios que a utiliza: $[\mathrm{S}]=$ Serviço; $[\mathrm{P}]=$ Produtos.

(b) RFID - Radio Frequency Identification

(c) ERP - Enterprise Resource Planning

(d) CRM - Customer Relationship Management

(e) ITIL - Information Technology Infrastructure Library

(f) COBIT - Control Objectives for Information and related Technology 
confiabilidade utilizamos a triangulação metodológica à base de uso de múltiplas fontes de informação (gerentes, engenheiros, técnicos, material publicado das empresas) e de diversas técnicas de coleta de informação (entrevistas, encontros fortuitos, observação direta). O processo de coleta de evidências envolveu a realização de mais de 20 entrevistas no âmbito das cinco empresas estudadas, além de observações diretas e consultas a arquivos e do- cumentos das empresas. Adicionalmente, após o término dos trabalhos de campo, foram enviados formulários respondentes selecionados nas empresas. Obtivemos 95\% de retorno, uma vez que eles já conheciam o trabalho.

As evidências relativas aos eventos relacionados às capacidades tecnológicas de cada empresa foram inicialmente dispostas em matrizes, listando as atividades de cada função tecnológica. Esse procedimento permitiu a

\section{Quadro 3 - Empresas de software selecionadas para o estudo}

\begin{tabular}{|c|c|c|c|c|c|c|}
\hline $\begin{array}{l}\text { 응 } \\
\text { 은 } \\
\text { 뜰 } \\
\text { 은 }\end{array}$ & 헝 & 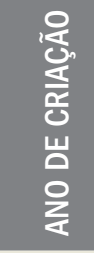 & $\sum_{\substack{1 \\
1}}$ & 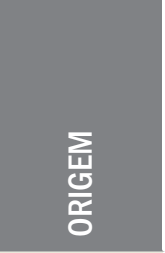 & 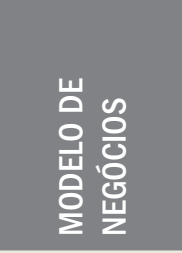 & DETALHES \\
\hline Alfa & $\begin{array}{l}\text { São } \\
\text { Paulo }\end{array}$ & 1995 & Média & Nacional & $\begin{array}{l}\text { Serviço / } \\
\text { Produto }\end{array}$ & $\begin{array}{l}\text { Fornecedora de serviços de software baseados em componen- } \\
\text { tes. Oferece soluções personalizadas através da integração e } \\
\text { customização de componentes de software pré-fabricados. }\end{array}$ \\
\hline Beta & $\begin{array}{l}\text { São } \\
\text { Paulo }\end{array}$ & 1991 & Média & Nacional & $\begin{array}{l}\text { Produto } \\
\text { customizável }\end{array}$ & $\begin{array}{l}\text { Empresa líder no mercado de software corporativo no Brasil. } \\
\text { Focada no mercado de pequenas e médias empresas, disputa } \\
\text { o mercado com grandes empresas estrangeiras e nacionais. } \\
\text { Atua no Brasil e em outros países da América Latina. }\end{array}$ \\
\hline Gama & $\begin{array}{l}\text { Rio de } \\
\text { Janeiro }\end{array}$ & 2000 & Pequena & Nacional & $\begin{array}{l}\text { Produto / } \\
\text { Serviço }\end{array}$ & $\begin{array}{l}\text { Pequena empresa que oferece softwares de relacionamento } \\
\text { com o cliente através da modalidade de Application Services } \\
\text { Provider }^{1} \text { (ASP) }\end{array}$ \\
\hline Delta & $\begin{array}{l}\text { Rio de } \\
\text { Janeiro }\end{array}$ & 1990 & Grande & Estrangeira & Serviço & $\begin{array}{l}\text { Unidade de desenvolvimento de soluções de uma grande mul- } \\
\text { tinacional localizada no Rio de Janeiro. Oferece serviços de } \\
\text { fábrica de software para outras unidades da empresa-mãe e } \\
\text { para clientes no Brasil. }\end{array}$ \\
\hline Epsilon & $\begin{array}{l}\text { Rio de } \\
\text { Janeiro }\end{array}$ & 2001 & Pequena & Nacional & $\begin{array}{l}\text { Produto / } \\
\text { Serviço }\end{array}$ & $\begin{array}{l}\text { Originária de uma incubadora de empresas, focada em de- } \\
\text { senvolvimento de produto de software e serviços agregados } \\
\text { aos produtos. Comercializa seus produtos diretamente e } \\
\text { através de canais de venda, que também são parceiros de } \\
\text { desenvolvimento. }\end{array}$ \\
\hline Zeta & $\begin{array}{l}\text { Rio de } \\
\text { Janeiro }\end{array}$ & 1998 & Pequena & Nacional & $\begin{array}{l}\text { Serviço / } \\
\text { Produto }\end{array}$ & $\begin{array}{l}\text { Empresa especializada em desenvolvimento de conteúdos de } \\
\text { e-learning e serviços complementares. Suas soluções são ofe- } \\
\text { recidas através de uma plataforma de e-learning distribuída } \\
\text { gratuitamente. Também originária de incubadora de empresas. }\end{array}$ \\
\hline Eta & $\begin{array}{l}\text { Rio de } \\
\text { Janeiro }\end{array}$ & 2000 & Pequena & Nacional & $\begin{array}{l}\text { Produto / } \\
\text { Serviço }\end{array}$ & $\begin{array}{l}\text { Pequena empresa originária de uma incubadora de empresas } \\
\text { focada no desenvolvimento de produtos e serviços de software } \\
\text { para telefonia móvel. }\end{array}$ \\
\hline Theta & $\begin{array}{l}\text { São } \\
\text { Paulo }\end{array}$ & 1994 & Grande & Estrangeira & Serviço & $\begin{array}{l}\text { Unidade de fábrica de software de uma grande multinacional. } \\
\text { Oferece serviços de desenvolvimento e manutenção de software } \\
\text { para clientes no Brasil e no exterior. }\end{array}$ \\
\hline
\end{tabular}

${ }^{1}$ Provedor de aplicações de software via serviço. Modelo de negócios no qual o software é vendido como serviço pago por utilização. 0 cliente não se preocupa com manutenção, custos de hardware e operação. 
reconstrução, à luz da tipologia no Quadro 1, das trajetórias tecnológicas e identificação do tempo necessário para acumular níveis específicos de capacidade tecnológica. Em seguida, as evidências foram estruturadas utilizando-se o Microsoft Access, a fim de facilitar os cálculos das velocidades de acumulação tecnológica das empresas.

\section{PRINCIPAIS RESULTADOS DO ESTUDO}

\section{Tipos e níveis atuais de capacidades tecnológicas nas empresas da amostra}

Esta seção apresenta os níveis e tipos de capacidades tecnológicas acumuladas pelas empresas da amostra no momento da realização desta pesquisa. O Quadro 4 mostra quais empresas acumularam níveis específicos de capacidades para cada uma das três funções tecnológicas examinadas.

\section{Taxa (velocidade) da acumulação de capacidades tecnológicas nas empresas da amostra}

Esta seção examina a taxa (velocidade) da acumulação das capacidades tecnológicas para as três funções tecnológicas nas empresas da amostra. Taxa ou velocidade significa o tempo, medido em anos, que cada empresa levou para alcançar níveis específicos de capacidade tecnológica para cada uma das três funções tecnológicas. As Figuras 1 a 4 ilustram a taxa (velocidade) média das empresas estudadas

\begin{tabular}{|c|c|c|c|c|}
\hline \multirow{2}{*}{\multicolumn{2}{|c|}{ NIVEIS DE CAPACIDADE }} & \multicolumn{3}{|c|}{ CAPACIDADES TECNOLÓGICAS } \\
\hline & & ENGENHARIA DE SOFTWARE & PRODUTOS E SERVIÇOS & PROCESSOS \\
\hline \multirow{3}{*}{$\begin{array}{l}\frac{\pi}{\pi} \\
\frac{\pi}{0} \\
\frac{0}{0} \\
0 \\
\underline{0}\end{array}$} & $\begin{array}{c}\text { Inovação Avançada } \\
\text { (próxima à fronteira internacional) } \\
\text { (Nível 6) }\end{array}$ & $\begin{array}{l}\text { Theta } \\
(12,5 \%)\end{array}$ & não alcançado & $\begin{array}{c}\text { Delta } \\
\text { Theta } \\
(25,0 \%)\end{array}$ \\
\hline & $\begin{array}{l}\text { Inovação Intermediária } \\
\text { (Nível 5) }\end{array}$ & $\begin{array}{c}\text { Eta } \\
\text { Beta } \\
\text { Delta } \\
\text { Theta } \\
(50,0 \%)\end{array}$ & $\begin{array}{c}\text { Eta } \\
\text { Beta } \\
\text { Delta } \\
\text { Theta } \\
(50,0 \%)\end{array}$ & $\begin{array}{l}\text { Delta } \\
\text { Theta } \\
(25,0 \%)\end{array}$ \\
\hline & $\begin{array}{l}\text { Inovação Básica } \\
\text { (Nível 4) }\end{array}$ & $\begin{array}{l}\text { Todas } \\
(100 \%)\end{array}$ & $\begin{array}{c}\text { Zeta } \\
\text { Epsilon } \\
\text { Alfa } \\
\text { Beta } \\
\text { Delta } \\
\text { Theta } \\
(87,5 \%)\end{array}$ & $\begin{array}{c}\text { Alfa } \\
\text { Beta } \\
\text { Delta } \\
\text { Theta } \\
(50,0 \%)\end{array}$ \\
\hline \multirow[t]{3}{*}{ 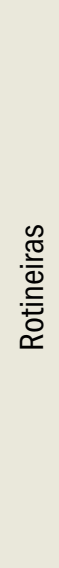 } & $\begin{array}{l}\text { Operação Avançada (world-class) } \\
\text { (Nível 3) }\end{array}$ & $\begin{array}{l}\text { Todas } \\
(100 \%)\end{array}$ & $\begin{array}{l}\text { Todas } \\
(100 \%)\end{array}$ & $\begin{array}{l}\text { Gama } \\
\text { Zeta } \\
\text { Epsilon } \\
\text { Alfa } \\
\text { Beta } \\
\text { Delta } \\
\text { Theta } \\
(87,5 \%)\end{array}$ \\
\hline & $\begin{array}{l}\text { Operação Intermediária } \\
\text { (Nível 2) }\end{array}$ & $\begin{array}{l}\text { Todas } \\
(100 \%)\end{array}$ & $\begin{array}{l}\text { Todas } \\
(100 \%)\end{array}$ & $\begin{array}{l}\text { Todas } \\
(100 \%)\end{array}$ \\
\hline & $\begin{array}{l}\text { Operação Básica } \\
\text { (Nível 1) }\end{array}$ & $\begin{array}{l}\text { Todas } \\
(100 \%)\end{array}$ & $\begin{array}{l}\text { Todas } \\
(100 \%)\end{array}$ & $\begin{array}{l}\text { Todas } \\
(100 \%)\end{array}$ \\
\hline
\end{tabular}


para acumularem capacidades para uma das três funções tecnológicas aqui examinadas: engenharia de software, produtos e serviços, e processos.

A Figura 2 ilustra graficamente a velocidade de acumulação de capacidades tecnológicas nas empresas da amostra para a função engenharia de software. Os dados apresentados demonstram que as empresas da amostra seguiram direções semelhantes, porém com diferentes velocidades em sua acumulação de capacidades tecnológicas.

Cinco das oito empresas da amostra $(62,5 \%)$ iniciaram suas operações no nível extrabásico (nível 2) de capacidades para engenharia de software. Em níveis rotineiros, essa função tecnológica é fundamentalmente técnica. Portanto, o conhecimento tácito dos sócios ou de engenheiros experientes foi suficiente para que essas empresas iniciassem suas operações já com capacidades tecnológicas acumuladas. As empresas Zeta e Alfa, no entanto, iniciaram suas atividades no nível básico (nível 1), pois ambas foram criadas por empreendedores que não tinham experiência no desenvolvimento de software. Por outro lado, a empresa Theta herdou da empresa-mãe não somente engenheiros experientes, mas também ferramentas e conhecimento explícito em forma de manuais, ferramentas e processos. Dessa forma, a empresa já iniciou suas atividades no nível pré-intermediário (nível 3).

É importante frisar que as empresas mais jovens da amostra - Epsilon, Eta, Gama e Zeta - acumularam capacidades tecnológicas nos níveis pré-intermediário e intermediário em uma velocidade maior que as empresas mais antigas - Alfa, Beta, Delta e Theta. Todavia, dessas empresas, somente a Eta conseguiu alcançar o nível intermediário superior (nível 5).Para a função tecnológica engenharia de software, a velocidade de acumulação de capacidades inovadoras aumenta para cada nível alcançado; em outras palavras, as empresas aceleram a acumulação de capacidades tecnológicas à medida que atingem níveis superiores de capacidade. Entretanto, para as capacidades rotineiras, o processo de acumulação da empresa Alfa ocorreu de forma contrária: os níveis mais altos levaram mais tempo que os níveis mais baixos.

A Figura 3 ilustra graficamente a velocidade de acumulação de capacidades tecnológicas nas empresas da amos-

Figura 1 - Taxa (velocidade) média de acumulação de capacidades tecnológicas

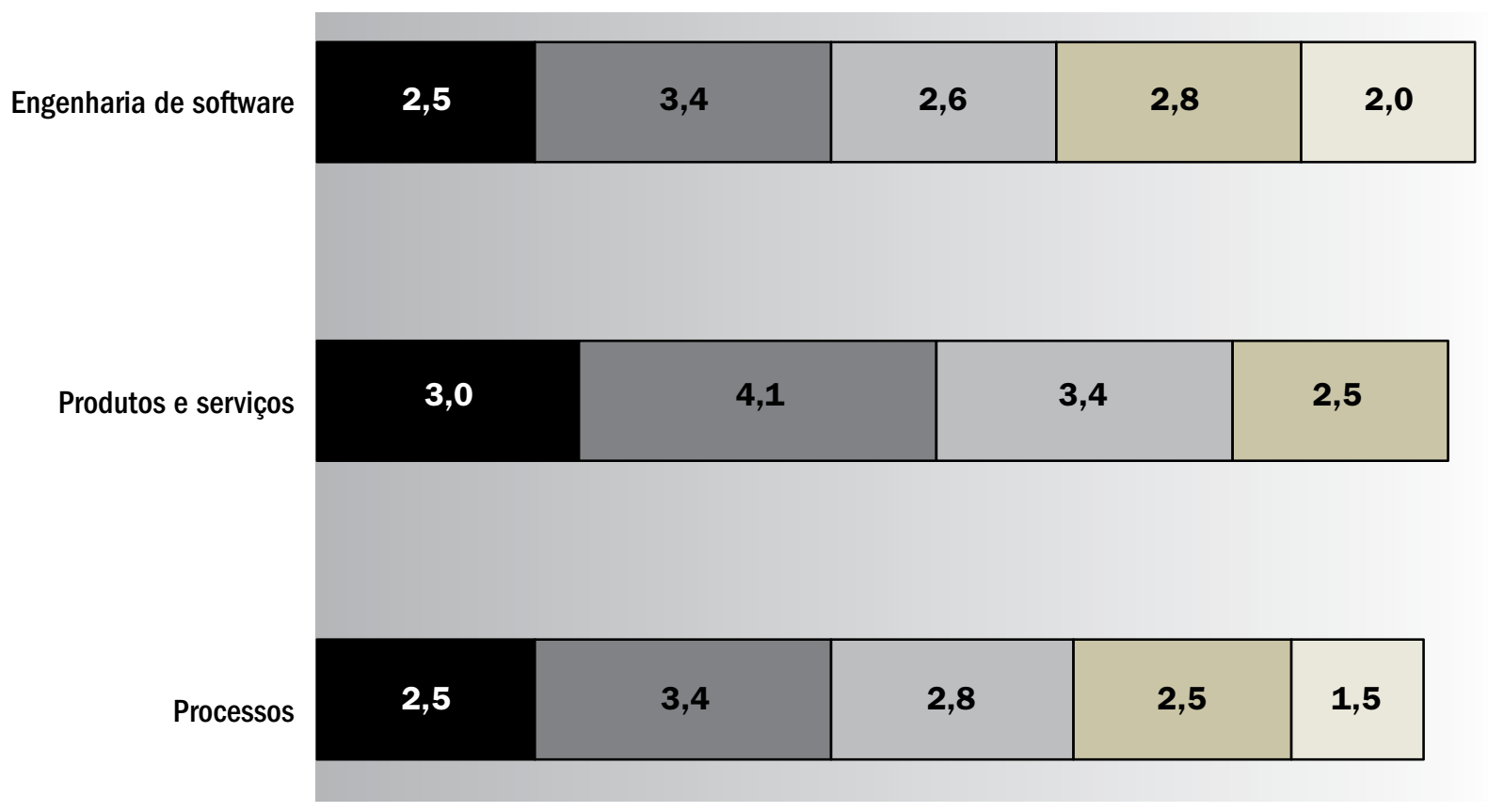

Nível $1 \rightarrow$ Nível 2

Nível $3 \rightarrow$ Nível 4

Nível $5 \rightarrow$ Nível 6
Nível $2 \rightarrow$ Nível 3

Nível $4 \rightarrow$ Nível 5 
tra para a função produtos e serviços. Essa figura indica que a direção de acumulação de capacidades tecnológicas nessa função foi parcialmente homogênea para as empre- sas da amostra, contudo a velocidade de acumulação foi bastante diversa.

Duas empresas da amostra (25\%), Gama e Zeta, inicia-

Figura 2 - Velocidade de acumulação de capacidades tecnológicas para engenharia de software

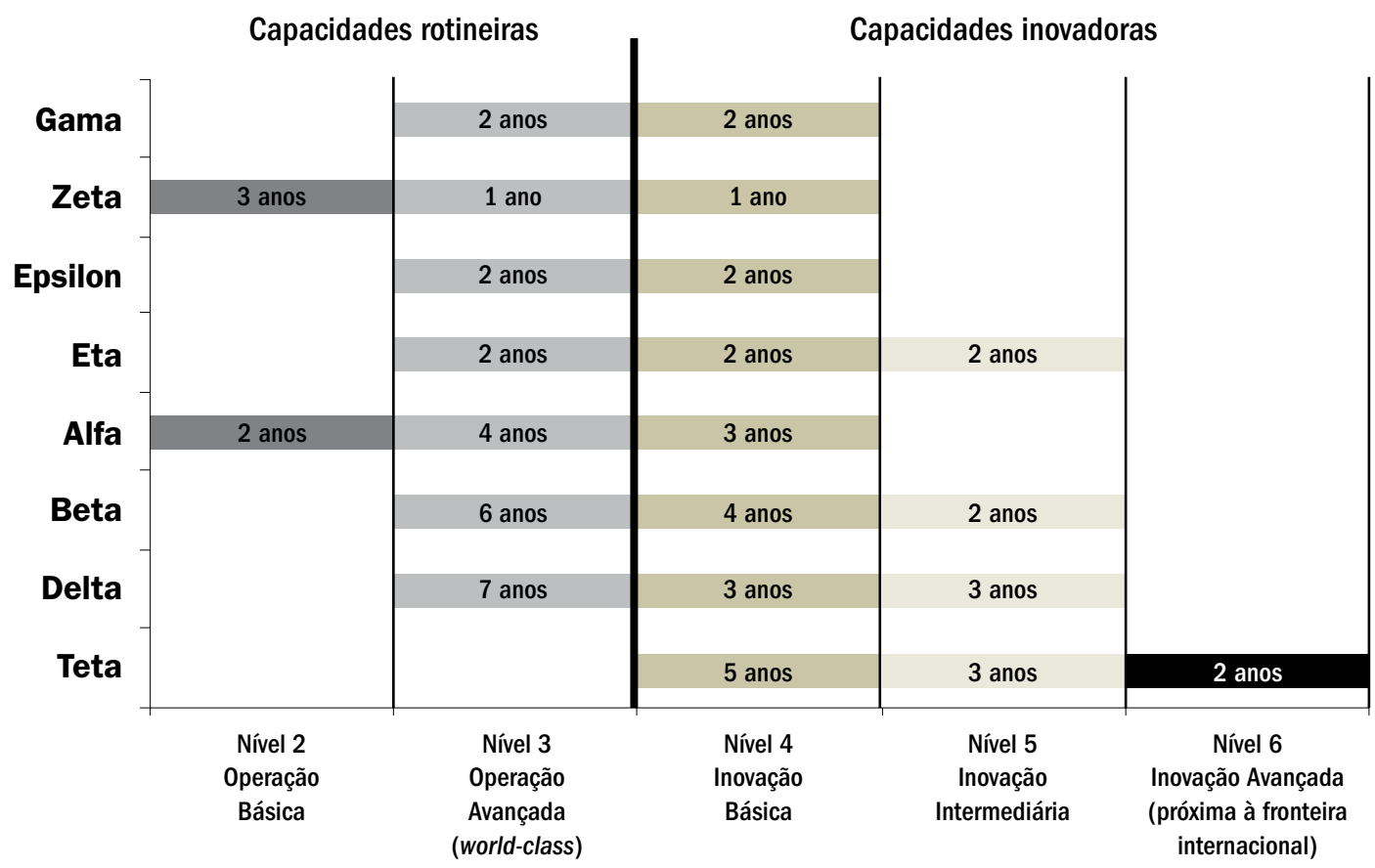

Figura 3 - Velocidade de acumulação de capacidades tecnológicas para produtos e serviços

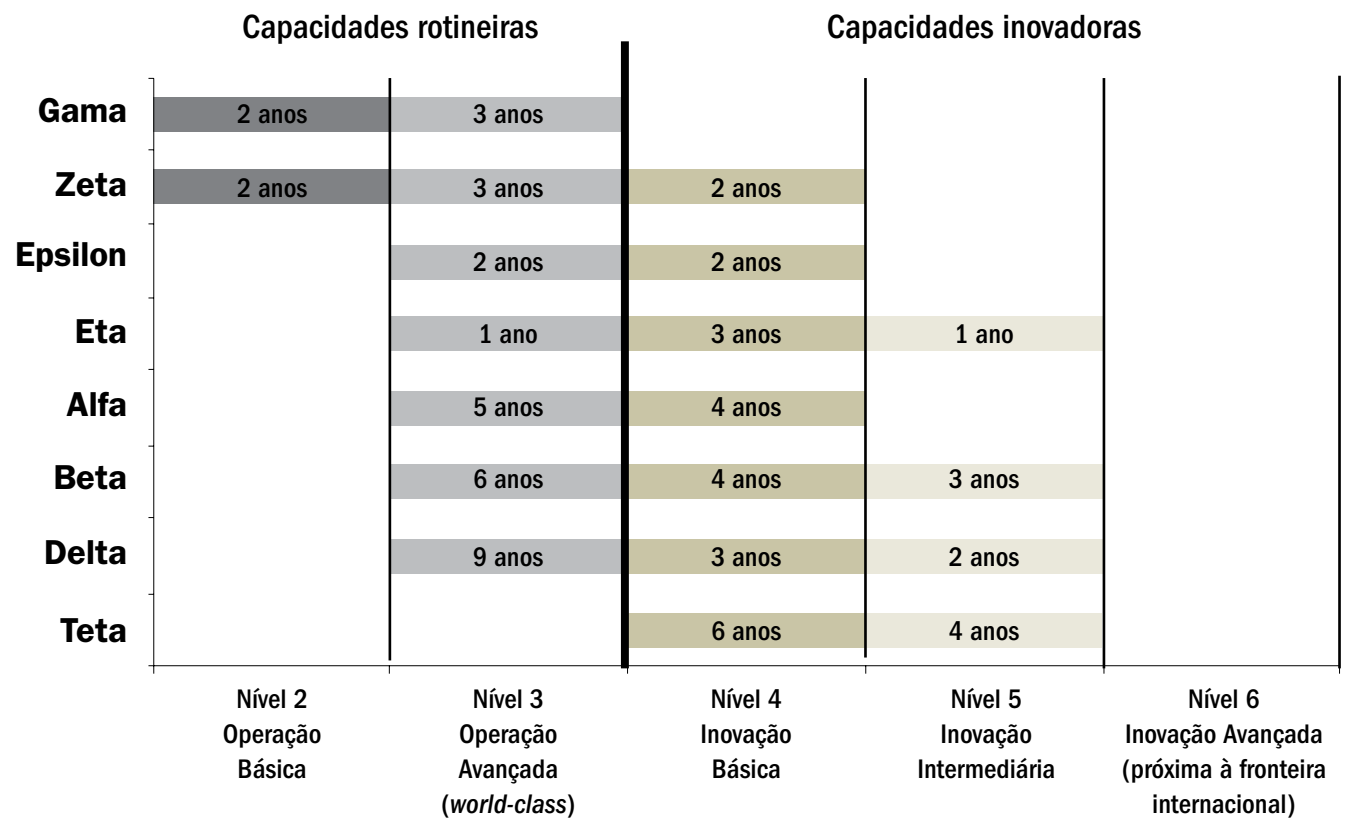


ram suas operações no nível básico (nível 1) de capacidades tecnológicas para produtos e serviços. Essas empresas alcançaram o nível pré-intermediário com a mesma velocidade, no entanto a empresa Gama ainda não alcançou o nível intermediário (nível 4). Essa empresa passou por uma transformação em seu modelo de negócios que a colocou em um processo de acumulação de capacidades para alcançar a concorrência. De fornecedora de serviços de baixo valor agregado, a empresa passou a oferecer produtos de software em mercados de grande competição. Essa mudança exigiu o engajamento em um processo de acumulação de capacidades na função tecnológica de produtos e serviços, que ainda não alcançou os resultados desejados pela empresa.

Das empresas mais novas, somente a Gama ainda não alcançou níveis de capacidades inovadoras, porém apenas a empresa Eta conseguiu acumular capacidades tecnológicas no nível intermediário superior (nível 5). A velocidade de acumulação dessas empresas foi superior à velocidade das empresas mais antigas. A direção e a velocidade de acumulação de capacidades da empresa Eta nessa função tecnológica são bem diversas das outras empresas da amostra. A empresa atingiu o nível intermediário superior (nível 5) em uma velocidade muito superior à das outras empresas. Em apenas cinco anos, a empresa saiu do nível extrabásico (nível 2), do qual iniciou sua operação, e alcançou o nível intermediário superior (nível 5). É pos- sível perceber que a empresa tem um foco muito grande na aquisição de conhecimento técnico e de produtos, com isso a empresa foi capaz de acumular capacidades tecnológicas em um mercado bastante inovador, que é o mercado de software para celulares.

O período de estagnação da empresa Delta fica novamente evidente na acumulação de capacidades tecnológicas para a função de produtos e serviços. A empresa levou nove anos para atingir o nível pré-intermediário (nível 3), mas depois acelerou bastante sua velocidade de acumulação de capacidades, alcançando os níveis intermediário (nível 4) e intermediário superior (nível 5) em três e dois anos, respectivamente.

$\mathrm{Na}$ função tecnológica de produtos e serviços, a velocidade de acumulação de capacidades rotineiras diminuiu à medida que os níveis aumentaram. Entretanto, para os níveis de capacidades inovadoras, a regra foi confirmada e a velocidade aumentou para os níveis mais avançados.

A Figura 4 ilustra graficamente a velocidade de acumulação de capacidades tecnológicas nas empresas da amostra para a função processos. Essa figura indica que a direção de acumulação de capacidades tecnológicas nessa função foi parcialmente homogênea para as empresas da amostra, no entanto a velocidade de acumulação foi muito diversa.

Quatro empresas da amostra (50\%) iniciaram suas operações no nível básico na função tecnológica de pro-

Figura 4 - Velocidade de acumulação de capacidades tecnológicas para processos

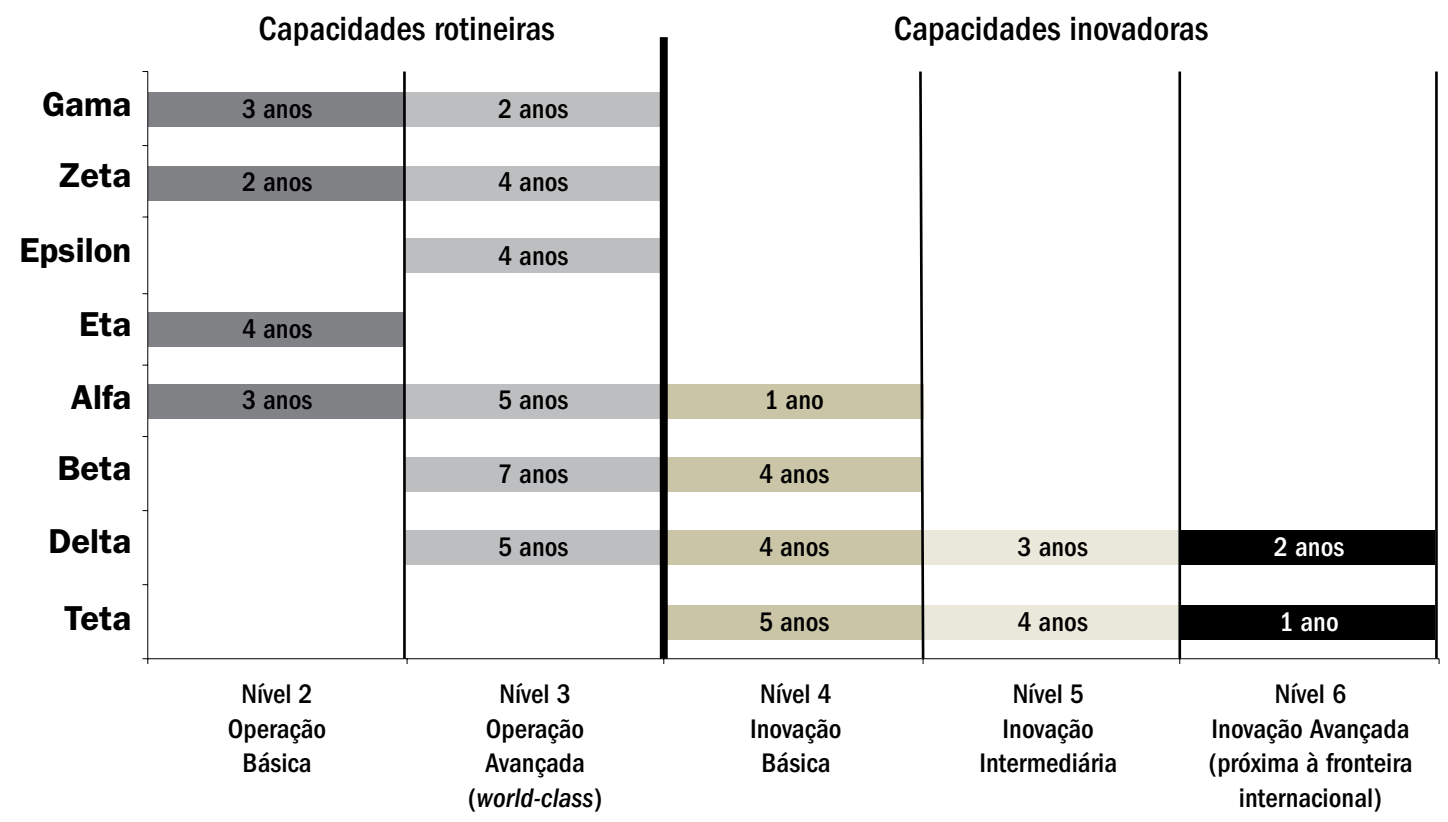


cessos. Três iniciaram no nível extrabásico (nível 2) e somente uma empresa iniciou suas operações no nível pré-intermediário (nível 3). Novamente, a herança das capacidades da empresa-mãe foi um fator importante para as empresas que iniciaram suas operações em um nível de capacidades mais avançado.

As empresas mais novas da amostra não alcançaram níveis de capacidades inovadoras para essa função tecnológica. A velocidade de acumulação de capacidades para essa função foi mais lenta para essas empresas: três delas levaram até quatro anos para acumular capacidades nos níveis rotineiros. Ainda assim, a velocidade dessas empresas foi maior que a das empresas mais antigas.

Em relação aos tipos e níveis atuais de capacidades tecnológicas:

1) Foi encontrada diversidade tanto entre empresas como entre funções tecnológicas específicas dentro de empresas.

2) A acumulação de capacidades tecnológicas nas empresas pesquisadas mostrou-se assimétrica entre as empresas, tanto no que se refere às capacidades acumuladas quanto à velocidade dessa acumulação. Ou seja, ao longo de sua existência, as empresas da amostra acumularam capacidades tecnológicas de diferentes tipos e níveis e o fizeram em diferentes velocidades.

3) Foi identificado que as empresas mais antigas, ao longo do processo de acumulação, passaram por períodos de pouca acumulação, caracterizando uma zona de conforto na qual as empresas obtinham bons resultados sem precisar evoluir. Com a rápida evolução do mercado de software e o aumento da competição, essas empresas perderam essa posição e foram impelidas a acelerar a acumulação de capacidades para se manterem competitivas.

\section{CONCLUSÕES E IMPLICAÇÕES}

Este artigo visou examinar a direção e a taxa (velocidade) de acumulação tecnológica em oito empresas de software no Rio de Janeiro e em São Paulo (1990-2006), por meio de extensivo trabalho de campo. Os dados de taxa (velocidade) apresentados nesta pesquisa permitem que os gestores tenham um exemplo empírico do tempo necessário para a acumulação de capacidades tecnológicas para cada função tecnológica, ajudando-os a estabelecer prazos e expectativas de acordo com sua estratégia corporativa. No que se refere à estratégia de pesquisa, o estudo aqui apresentado baseou-se em evidências empíricas de primeira mão reunidas através de extenso trabalho de campo. Essa estratégia gera um volume considerável de evidências empíricas de longo prazo, tanto qualitativas quanto quantitativas, fundamentais para a sustentação das análises das nuanças dos processos de desenvolvimento de capacidade nas empresas examinadas.

Uma das principais limitações deste estudo é não ter examinado as fontes para a acumulação das capacidades tecnológicas - ou seja, o papel dos processos subjacentes de aprendizagem - para explicar as diferenças encontradas entre as empresas em termos do modo e da velocidade de acumulação de suas capacidades tecnológicas. Também não foram examinados os impactos da acumulação de capacidades tecnológicas para o aprimoramento de indicadores de desempenho operacional, de mercado e econômico-financeiros nas empresas estudadas. Estudos futuros poderão examinar tais questões.

Ou seja, o desenho à base de longo prazo e a ênfase no tempo de desenvolvimento de capacidade tecnológica permitirão um real entendimento do processo de desenvolvimento tecnológico em nível de empresas e de setores industriais. Do contrário, todas as recomendações corporativas e governamentais sobre dinâmica, trajetórias e mudança industrial e tecnológica - fortemente presentes em estudos sobre inovação - não passarão de mera retórica e especulação.

Este estudo não sugere que existam quaisquer tipos de taxas de acumulação de capacidade melhores ou corretas baseadas em experiências anteriores. Em vez disso, demonstra a necessidade de aceitação da variedade presente nas trajetórias de desenvolvimento tecnológico, em termos de modo e velocidade. O estudo analisa, substanciado por evidências e base metodológica, como o tempo que se leva, em setores específicos, para avançar dos níveis básicos de capacidades tecnológicas para os níveis seguintes é importante para orientar a estratégia de investidores, governos e empresas. No caso da utilização de mecanismos de incentivo fiscal, sejam eles genéricos ou ligados ao desempenho de inovação na presença de concorrência estrangeira, a noção de taxas de capacidade de desenvolvimento tecnológico deve ajudar os governos a definir o tempo aproximado em que as empresas teriam de começar a operar sem os referidos incentivos. Isso poderia funcionar como um mecanismo contra a estagnação do processo de inovação.

De fato, os pesquisadores precisam aprofundar suas investigações e análises para esclarecer melhor os retornos do aprendizado, de modo a corresponder às expectativas de gerentes, executivos corporativos, investidores e gestores públicos relacionadas, por exemplo, (i) aos reais custos envolvidos nos esforços de aprendizado e reaprendizado, 
assim como nas consequências mercadológicas, econômicas e sociais do não-aprendizado e do desaprendizado; e (ii) à maneira pela qual empresas e governos poderiam lidar com a natureza de longo prazo do retorno dos processos de aprendizado em face das expectativas de curto e de médio prazo e aos mandatos dos executivos corporativos e gestores públicos. As pesquisas como as que foram implementadas em alguns países em desenvolvimento, como Argentina, Brasil, Chile, Uruguai e México, tendo como base o Manual de Oslo e a experiência europeia, têm sido vistas como alternativas para superar as dificuldades dos estudos aprofundados nas empresas e nas indústrias. No entanto, como em qualquer tipo de estudo agregado, elas escondem importantes nuanças de mudanças tecnológicas dentro dos setores empresariais e industriais. $\mathrm{Na}$ verdade, deve-se ter muita cautela ao se utilizar os resultados das pesquisas de inovação como única fonte/base na tentativa de se entender a realidade (e a dinâmica) dos países emergentes.

Mais especificamente, os resultados de tais pesquisas de inovação, especialmente aquelas baseadas em desenhos estáticos, informação agregada e análises baseadas em indicadores convencionais (como, por exemplo, gastos em P\&D e em estatísticas de patentes) não levam em consideração variações importantes de heterogeneidades e similaridades em nível de empresas (intrafirma) nos processos de desenvolvimento de capacidade no que se refere a funções tecnológicas específicas em diferentes períodos. Essas nuanças são fundamentalmente importantes para se compreender a taxa (velocidade ou dinamismo) da capacidade de desenvolvimento nos países em desenvolvimento (KATZ, 1987; BELL e PAVITT, 1993, 1995; ARIFFIN, 2000; FIGUEIREDO, 2001, 2008; TACLA e FIGUEIREDO, 2006; BELL, 2006). De fato, em relação à profusão recente de pesquisas de inovação em países em desenvolvimento, Bell (2006, p. 36) avisa: "[...] apesar de se tornarem valiosos complementos para outros tipos de informação, não podem ser considerados substitutos."

$\mathrm{Na}$ verdade, uma combinação de análise agregada no âmbito industrial e de estudos em nível de empresas, a partir de uma perspectiva dinâmica, seria valiosa para esclarecer se e como as empresas e indústrias de economias emergentes acumulam (ou não) certos níveis de capacidade ao longo do tempo. Isso pode significar um avanço crucial nos esforços para gerar recomendações concretas, mais realistas e viáveis no processo decisório no tocante à alocação de recursos voltados para as questões de inovação no contexto de economias emergentes. Isso representa um desafio para os pesquisadores de desenvolvimento ao tentar combinar as pesquisas com os estudos no âmbito de setores industriais e de empresas e as análises comparativas longitudinais da construção da capacidade e do aprendizado, de modo a formular interpretações significativas da dinâmica dos processos de acumulação tecnológica das empresas e indústrias nos países em desenvolvimento.

\section{NOTA DE AGRADECIMENTO}

Este artigo deriva da dissertação de mestrado de Eduardo Miranda, sob a supervisão de Paulo N. Figueiredo, aprovada na FGV-EBAPE. Os autores agradecem às empresas que participaram do estudo de campo, como também são gratos a dois avaliadores anônimos da RAE pelos comentários e sugestões que contribuíram para o aprimoramento do texto.

\section{REFERÊNCIAS}

ABERNATHY, W; CLARK, K. B. Innovation: mapping the winds of creative destruction. Research Policy, v. 14, n. 1, p. 3-22, 1985.

AMABILE, T. M. Creativity in context. Boulder: Westview Press, 1996.

AMSDEN, A. H. The rise of the rest: challenges to the West from late_industrializing economies. Oxford: Oxford University Press, 2000.

AMSDEN, A. H; TSCHANG, F. T. A new approach to assessing the technological complexity of different categories or $\mathrm{R} \& \mathrm{D}$ (with examples from Singapore). Research Policy, v. 32, n. 4, p. 553-572, 2003.

ANDERSON, P; TUSHMAN, M. L. Technological discontinuities and dominant designs: a cyclical model of technological change. Administrative Science Quarterly, v. 35, n. 4, p. 604-633, 1990.

ARCHIBUGI, D; PIANTA, M. Measuring technological change through patents and innovation surveys. Technovation, v. 16, n. 9, p. 451-468, 1995

ARIFFIN, N. The internationalisation of innovative capabilities: the malaysian electronics industry. 2000. Thesis (PhD), SPRU, University of Sussex, Brighton, 2000

ARIFFIN, N; BELL, M. Firms, politics and political economy: patterns of subsidiary-parent linkages and technological capability_building in electronics TNC subsidiaries in Malaysia. In: JOMO, K. S; FELKER, G; RASIAH, R. (Eds) Industrial technology development in Malaysia. London: Routledge, 1999.

ARIFFIN, N; FIGUEIREDO, P. N. Internationalization of innovative capabilities: counter-evidence from the electronics industry in Malaysia and Brazil. Oxford Development Studies, v. 32, n. 4, p. 559-583, 2004

BASKERVILLE, R; PRIES-HEJE, J. Knowledge capability and maturity in software management. Database for Advances in Information Systems, v. 30, n. 2, p. 26-43, 1999 
BELL, M. Learning and the accumulation of industrial technological capacity in developing countries. In: FRANSMAN, M; KING, K. Technological capability in the Third World. London: Macmillan, 1984. p. 187-209.

BELL, M. Time and technological learning in industrializing countries: how long does it take? How fast is it moving (if at all)? International Journal of Technology Management, v. 36, n. 1-3, p. 25-42, 2006.

BELL, M; HOBDAY, M; ABDULLAH, S; ARIFFIN, N; MALIK, J. Aiming for 2020: a demand-driven perspective on industrial technology in Malaysia. Malaysia, Brighton: SPRU, University of Sussex, 1995. (Final report for the World Bank and Ministry of Science, Technology and the Environment).

BELL, M; PAVITT, K. Technological accumulation and industrial growth: contrast between developed and developing countries. Industrial and Corporate Change, v. 2, n. 2, p. 157-210, 1993.

BELL, M; PAVITT, K. The development of technological capabilities: technology and international competitiveness. Washington: The World Bank, 1995.

CHANG, H-J. Kicking away the ladder: infant industry promotion in historical perspective. Oxford Development Studies, v. 31, n. 1, p. 21-32, 2003.

CHANG, H-J. Bad Samaritans: rich nations, poor policies and the threat to the developing world. London: Random House Business Books, 2007.

CHOUNG, J-Y; HWANG, H-R.; YANG, H. The co-evolution of technology and institution in the Korean information and communications industry. International Journal of Technology Management, v. 36, n. 1-3, p. 249-266, 2006.

CHRISTENSEN, C. M. Exploring the limits of the technology S-curve: component technologies. Production and Operations Management, v. 1, n. 4, p. 334-356, 1992.

DAHLMAN, C; FONSECA, F. From technological dependence to technological development: the case of the USIMINAS steel plant in Brazil. [S.1]: IBD/ ECLA Research Programme, 1978. (Working Paper n. 21).

DAHLMAN, C; Westphal, L. Technological effort industrial development - an interpretative survey of research. In: STEWART, F; JAMES, J. (Eds) The economics of new technology in development countries. London: Frances Printer, 1982. p. 105-137.

DOSI, G. Sources, procedures and microeconomic effects of innovation. Journal of Economic Literature, v. 26, n. 3, p. 1120-1171, 1988.

DUTRÉNIT, G. From knowledge accumulation to strategic capabilities: knowledge management in a Mexican glass firm. 1998. Thesis (PhD), SPRU, University of Sussex, Brighton, 1998.

DUTRÉNIT, G. Learning and knowledge management in the firm: from knowledge accumulation to strategic capabilities. Cheltenham: Edward Elgar, 2000.

FIGUEIREDO, P. N. Technological learning and competitive performance. Northampton, MA; Cheltenham, UK: Edward Elgar: 2001.
FIGUEIREDO, P. N. Learning, capability accumulation and firms differences: evidence from latecomer steel. Industrial and Corporate Change, v. 12, n. 3, p. 607-643, 2003.

FIGUEIREDO, P. N. Aprendizagem tecnológica e inovação industrial em economias emergentes: uma breve contribuição para o desenho e implementação de estudos empíricos e estratégias no Brasil. Revista Brasileira de Inovação, v. 3, n. 2, p. 323-361, 2004.

FIGUEIREDO, P. N. Industrial policy changes and firm-level technological capability development: evidence from Northern Brazil. World Development, v. 36, n. 1, p. $55-88,2008$

FIGUEIREDO, P. N. Gestão da inovação: conceitos, métricas e experiências de empresas no Brasil. Rio de Janeiro: LTC, 2009.

FREEMAN, C. The economics of industrial innovation. London: Pinter, 1982

GERSCHENKRON, A. Economic backwardness in historical perspective. Cambridge, MA: Harvard University Press, 1962.

GRILICHES, Z. Hybrid corn: an exploration in the economics of technological change. Econometrica, n. 25, p. 510-522, Oct. 1957.

HENDERSON, R; CLARK, K. Architectural innovation: the reconfiguration of existing product technologies and the failure of established firms. Administrative Science Quartely, v. 35, n. 1, p. 9-30, 1990.

Hobday, M. Innovation in East Asia: the challenge to Japan. Aldershot, UK: Edward Elgar, 1995.

Hobday, M. Innovation in Asia industrialization: a Gerschenkronian perspective. Oxford Development Studies, v. 31, n. 3, p. 294-314, 2003.

HWANG, H-R. Organisational capabilities and organisational rigidities of Korean Chaebol: case studies of semi-conductor (DRAM) and personal computer (PC) products. 1998. Thesis (PhD), SPRU, University of Sussex, Brighton, 1998.

KATZ, J. Importación de tecnología, aprendizaje y industrialización dependiente. México: Fondo de Cultura Económica, 1976.

KATZ, J. Domestic technology generation in LDCs: a review of research findings. In: KATZ, J. (Ed) Technology generation in Latin American manufacturing industries. New York: St Martin's Press, 1987.

KIM, L. The dynamics of Samsung's technological learning in semiconductors. California Management Review. v. 39, n. 3, p. 142-155, 1997.

LALL, S. Technological learning in the Third World: some implications of the technology exports. In: STWEART, F; JAMES, J. (Eds) The economics of new technology in developing countries. London: Francis Pinter, 1982.

LALL, S. Learning to industrialise: the acquisition of technological capability by India. London: MacMillan, 1987.

LALL, S. Building industrial competitiveness in developing countries. Paris: OECD, 1990 
LALL, S. Technological capabilities and industrialization. World Development, v. 20, p. 165-186, 1992.

LANDES, D. S. Technological change and industrial development in Western Europe from 1750 to the present. Cambridge: Cambridge University Press, 1969.

LIU, J-J; QUIAN, J-Y; CHENG, J. Technological learning and firm-level technological capability building: analytical framework and evidence from Chinese manufacturing firms. International Journal of Technology Management, v. 36, n. 1-3, p. 190-208, 2006.

MALERBA, F. Learning by firms and incremental technical change. The Economic Journal, v. 102, n. 413, p. 845-859, 1992.

MALERBA, F. Sectoral systems: how and why innovation differs across sectors. In: FAGERBERG, J; MOWERY, D. C; NELSON, R. R. (Eds) The Oxford handbook of innovation. Oxford: Oxford University Press, 2005. p. 380-406.

MANSFIELD, E. Technical change and the rate of imitation. Econometrica, v. 29 , n. 4 , p. $741-765,1961$.

MOWERY, D. C; ROSENBERG, N. Government policy and innovation in the commercial aircraft industry. In: NELSON, R. R. (Ed) Government and technical progress: a cross-industry analysis. New York: Pergamon Press, 1982. p. 1925-1975.

NASSCOM. NewsLine. Andhra Pradesh, n. 43, May, 2005. Disponível em: http://www.nasscom.org/newline/issue43/NL-May05.pdf. Acesso em 04.03.2005.

NELSON, R. A diffusion model of international productivity differences in manufacturing industry. The Economic Review, v. 58, n. 5, p. $1219-$ 1248, 1968.

NELSON, R. Research on productivity growth and productivity differences: dead ends and new departures. Journal of Economic Literature, v. 19, n. 3, p. 1029-1064, 1981

NELSON, R. The changing institutional requirements for technological and economic catch up. International Journal of Technological Learning, Innovation and Development, v. 1, n. 1, p. 4-12, 2007.

NELSON, R; WINTER, S. An evolutionary theory of economic change. Cambridge, MA: Harvard University Press, 1982.

OECD. Information technology outlook-highlights. Paris: Organisation for Economic Co-operation and Development, 2002.

PATEL, P; PAVITT, K. The technological competencies of the World's largest firms: complex and path-dependent, but not much variety. Research Policy, v. 26, n. 2, p. 141-156, 1997.

PATTON, M. Q. Qualitative evaluation and research methods. 2nd ed. Newbury Park, CA: Sage, 1990.

PAVITT, K. Sectoral patterns of technical change: towards a taxonomy and a teory. Research Policy, v. 13, n. 6, p. 343-373, 1984.
PEREZ, C. Structural change and the assimilation of new technologies in the economic and social system. Futures, v. 15, n. 4, p. 357-375, 1983.

PEREZ, C; SOETE, L. Catching up in technology: entry barriers and windows of opportunity. In: DOSI, G; FREEMAN, C; NELSON, R; SILVERBERG, G; SOETE, L. (Eds) Technical change and economic theory. London: Pinter, 1988.

ROGERS, E. M. Diffusion of innovations. New York: The Free Press, 1983

ROSENBERG, N. Technological change in the machine tool industry, 1840-1910. Journal of Economic History, v. 23, n. 4, p. 414-443, 1963.

ROSENBERG, N. Inside the black-box. Cambridge: Cambridge University Press, 1982.

ROSENBERG, N; FRISCHTAK, C. (Eds) International technology transfer: concepts, measures and comparisons. New York: Praeger, 1985.

SCHUMPETER, J. Capitalism, socialism and democracy. New York: Harper, 1942.

SOFTEX. A indústria de software no Brasil: fortalecendo a economia do conhecimento. Campinas: SOFTEX, 2008.

SOFTEX. Perfil das empresas brasileiras exportadoras de software. Campinas: SOFTEX, 2005

STEWART, F; JAMES, J. Introduction. In: STWEART, F; JAMES, J. (Eds) The economics of new technology in developing countries. London: Frances Pinter, 1982.

STRASSMAN, W. P. Causes of technological stagnation manufacturing during early industrialization. Oxford Economic Papers, v. 19, n. 3, p. 345-358, 1963

TACLA, C. L; FIGUEIREDO, P. N. Aprendizagem e competências tecnológicas na indústria de bens de capital: o caso da Kvaerner Pulping do Brasil. In: Simpósio de Gestão da Inovação Tecnológica, 22, 2006, Salvador. Anais Salvador: ANPAD, 2006.

TESSLER, S; BARR, A. Software R\&D strategies of developing countries. In: Council on Foreign Relations' Study Group on the Globalization of Industrial R\&D, 1997, Stanford. Anais eletrônicos. Stanford: Stanford University, 1997.

TSCHANG, T. F; AMSDEN, A; SADAGOPAN, S. Measuring technological upgrading in the indian software industry: a framework of R\&D capabilities and business models. ADBI Publishing, 2003. Disponivel em: http:// www.adbi.org/research.publications. Acesso em 25.11.2009.

TSCHANG, T. F; XUE, L. The Chinese software industry: the implications of a changing domestic market for software enterprises. In: ARORA, A; GAMBARDELLA, A. From underdogs to tigers: the rise and growth of the software industry in Brazil, China, India, Ireland, and Israel. Oxford: Oxford University Press. 2005.

YU, F-L. T. Technological strategies and trajectories of Hong Kong's manufacturing firms. International Journal of Technology Management, v. 29, n. 1-2, 2005 